\title{
Abuela to mother motivational interviewing intervention to reduce low-nutritive simple carbohydrate intake
}

\author{
Trina Aguirre ${ }^{1 *}$, Susan Wilhelm ${ }^{1}$ and Ann Koehler ${ }^{2}$ \\ *Correspondence: taguirre@unmc.edu \\ 'University of Nebraska Medical Center College of Nursing-West Nebraska Division, USA. \\ ${ }^{2}$ University of Nebraska Medical Center College of Public Health-Center for Global Health and Development, USA.
}

\begin{abstract}
Background: Mexican-American children have the highest rates of childhood obesity of any ethnic group [1]. Because MexicanAmerican mothers follow the advice of abuelas (respected grandmothers in the Mexican-American community) more than that of health care providers [2], this pilot study evaluated the efficacy of using abuelas to deliver a motivational interviewing intervention to encourage Mexican-American mothers to limit their children's low-nutritive simple carbohydrate intake. Specific questions were whether or not 1) abuelas could deliver a motivational interviewing intervention, 2) abuelas could recruit and retain participants, and 3) mothers altered their attitudes/beliefs, perceived norms, perceived behavioral control (self-efficacy), intent and behavior of limiting their children's low-nutritive simple carbohydrate intake.

Methods: Two abuelas were recruited and trained to deliver a motivational interviewing intervention. The abuelas recruited 6 mothers to participate in the study. Assessments and interventions occurred at baseline and 1 month. Attitude/beliefs, perceived norm and perceived behavioral control (self-efficacy) were measured using sub-scales of the Healthy Diet Survey [3], intent was measured using an Intent Questionnaire, and behavioral change was assessed using a short-form food frequency questionnaire. A Wilcoxon test $(\alpha=0.05)$ was used to evaluate changes in responses between baseline and 1 month.

Results: The abuelas were successfully trained in motivational interviewing and reliably delivered the intervention. The abuelas recruited 6 mothers and all 6 participated through the entire study. All mothers felt it was important to limit their children's' low-nutritive simple carbohydrate intake $(M=9.83, \mathrm{SD}=.408)$ and scored their readiness to change as highly or extremely likely. Confidence in their ability to limit their children's low-nutritive simple carbohydrate intake increased $(\mathrm{z}=-2.041, \mathrm{p}=.041)$ between baseline $(M=6.33, S D=1.97)$ and 1 month $(M=9.67, S D=.82)$ for 5 of the mothers. The sixth scored her confidence as 10 (the maximum) at both assessments. Responses to the food frequency questionnaire suggest a trend towards limiting their children's low-nutritive simple carbohydrate intake.

Conclusions: This study demonstrated that recruitment, retention, and program delivery using abuelas were successful and the results suggest a trend towards mothers limiting their children's low-nutritive simple carbohydrates.
\end{abstract}

Keywords: Hispanic, abuela, childhood obesity, mothers, simple carbohydrates

\section{Introduction}

Mexican-American children have the highest rates of childhood obesity of any ethnicity (more than $38 \%$ ), with children age 2-6 years having almost twice the rate of obesity (17\%) of white children (9.1\%) [1]. Rural areas in this country have higher rates of obesity than urban areas [4]. This study was conducted in a rural mid-western area that is approximately $40 \%$ MexicanAmerican with an overweight prevalence among children of $31.5 \%$ [5]. Children who are obese are at higher risk for adult obesity and its co-morbidities including hypertension, diabetes, cardiovascular disease, joint disorders, psychological disorders, hyperlipidemia, cancers, and asthma [1]. Obese children consume on average three times the cost of health care resources as a normal-weight child [6]. The national cost of childhood obesity is estimated at approximately 11 billion dollars for children with private insurance and 3 billion dollars for those with Medicaid. Children diagnosed with obesity are two to three times more likely to be hospitalized. Obese children are far more likely to be diagnosed with mental health disorders than non-obese children [6]. These facts support the need for obesity prevention and treatment interventions during early childhood.

Obesity is a complex multifaceted disease with multiple factors that contribute to or promote greater than expected weight gain in childhood. Limiting LNSCI in young children has been associated with lower rates of childhood obesity [7]. Low-nutritive simple carbohydrate foods are those foods that contain high proportions of simple sugars [8]. These foods are rapidly digested and absorbed, resulting in rapid peaks in blood glucose and insulin followed by a trough in blood glucose which results in increased perceptions of hunger. Commonly these foods have little nutritional value [8]. Examples include processed and homemade foods made with white flour, sugar, and corn syrup such as white bread, tortillas, pastas, candies, sweetened beverages, fruit juices/drinks and sodas. Foods with high sugar content have been shown to contribute to 
the increasing prevalence of obesity in children [9]. Brekke reported a positive relationship between one year old children who had a high intake of LNSCl and child obesity [9]. Starc [10] reported that high dietary intake of $\mathrm{LNSCl}$ is associated with lower HDL-cholesterol concentrations that are an important coronary risk factor and should be considered in diet planning for children [11]. It is important to recognize that in both children and adults obesity is strongly related to increased triglycerides and low HDL cholesterol [12]. Therefore, limiting LNSCI is likely to decrease the risk of developing childhood obesity. Also notable is the relationship between mothers' weight or body mass index (BMI) and child's weight or BMI. Several studies have confirmed this positive relationship in Mexican-American populations [13-16]. Mothers' eating and feeding behaviors have been positively associated as well [17]. Therefore, it is important to understand the mothers' role in contributing to and preventing obesity, and to include the mother in interventions to solve childhood obesity.

Pre-school children are primarily reliant upon an adult, usually their mother, for the quantity and selection of food available to them [18]. That mother/child relationships may affect childhood obesity is well documented in the literature, though there have been few studies examining MexicanAmerican mother/child eating behaviors. Children's disregulated energy intake has been positively correlated with mothers' disinhibition (inability to control food intake) $[19,20]$. Furthermore, Mexican American mothers' dietary disinhibition has been associated with less healthy food choices for themselves and their children [21]. Restrictive parent-child feeding practices have been associated with higher child weight [22]. Clark recommends that parents offer healthy foods to their children (e.g., limiting LNSCI) and allow the child to decide how much to eat [18]. This approach promotes healthy eating and allows the child to self-regulate intake of healthy foods. Other than sugar sweetened beverages (e.g., soda), there is little literature on limiting low-nutritive simple carbohydrates to reduce or prevent the incidence of obesity. Literature on treating childhood obesity in rural America is also limited.

Given the difficulty of reversing obesity, it is preferable to prevent overweight/obesity from developing by intervening in early childhood [23-25]. Few interventions have targeted prevention and treatment of childhood obesity in preschool children [25-27]. Interventions involving Hispanic preschoolers are even more limited $[\mathbf{2 8 , 2 9 ]}$. A number of interventions have been trialed to treat childhood obesity with limited effectiveness. Few have focused on influencing attitude/beliefs, perceived behavioral control (self-efficacy), perceived norms, intent and limiting LNSCI behaviors among Mexican-American populations. Nutrition education programs generally focus on information dissemination, but have had limited effect on behavior change $[30,31]$. Nutrition education programs alone, which suggest specific diets, may be expensive and the Mexican-American populations in most communities are often poverty stricken and lack access to outlets providing inexpensive, healthy foods [32].

There is a growing body of literature that supports use of culturally appropriate interventions to facilitate behavior change [33]. We propose that using abuelas to deliver a Motivational Interviewing (MI) intervention to encourage Mexican-American mothers to limit their children's LNSCI would be more effective at producing behavior changes than other strategies because Mexican-American mothers follow the advice of abuelas (respected grandmothers in the Mexican-American community) more than that of health care providers [2]. If employing abuelas to deliver the MI intervention helps Mexican-American mothers limit lownutritive simple carbohydrate feeding behavior, it may help normalize their children's body composition and decrease their risks for childhood obesity and the associated co-morbidities.

This pilot study evaluated the efficacy of using abuelasto deliver a MI intervention, with the goal of positively changing Mexican-American mothers' attitudes/beliefs, perceived norms, perceived behavioral control (self-efficacy), intent to limit their children's LNSCl and actual behavior of limiting their children's LNSCI. MI is evidence-based and uses encouragement and non-confrontational methods to favorably change attitude/ beliefs, perceived norms, perceived behavioral control (selfefficacy) and intent to change behavior [34]. This approach is client-centered, empowering individuals to establish their own realistic goals for behavior change. It has been used extensively to change dietary intake, diabetes self-care, and addiction behaviors and is hypothesized to be an effective strategy for improving other health behaviors [35-37].

This pilot study evaluated whether or not 1) abuelas could be successfully trained to deliver a MI intervention to limit LNSCI following an algorithm2) abuelas could successfully recruit and retain participants and 3) mothers altered their attitudes/beliefs, perceived norms, perceived behavioral control (self-efficacy), intent to limit their children's LNSCI and actual behavior of limiting their children's LNSCI.

\section{Methods}

The framework for this pilot study was adapted from the Predicting and Changing Behavior Theory (PCBT) [38]. PCBT proposes that the primary determinants of behavior influence intention to engage in a particular behavior. These determinants include attitudes/beliefs (an individual's perception toward a behavior), perceived norms (including social pressures within a culture or family), and perceived behavioral control (self-efficacy or an individual's belief about the ease or difficulty of performing a behavior). The PCBT has been used to predict behaviors such as weight loss, physical activity and self-efficacy for healthy eating in Mexican-American populations [39-42].

We determined the mothers' attitude/belief score by summing the responses to the attitudes/beliefs sub-scale of The Healthy Diet Survey [3]. Higher scores indicated stronger attitudes/beliefs supporting limiting LNSCI. The Cronbach's alpha (a measure of internal consistency) for this sub-scale 
was .80 with a test-retest stability of $r=.81$ over 2 months [3].

We determined the mothers' normative belief score by summing the responses to the normative belief sub-scale of The Healthy Diet Survey [3]. Higher scores indicated greater normative belief for limiting LNSCl. Cronbach's alpha for this sub-scale was .77 with test-retest stability of $r=.80$ over 2 months [3].

We determined the mothers' self-efficacy (perceived behavioral control) score by summing the responses to the control belief sub-scale of The Healthy Diet Survey [3]. Higher scores indicated greater belief in ability to limit LNSCI. Cronbach's alpha for this sub-scale was .73 with a test-retest stability of $r=.76$ over 2 months [3].

We measured the mothers' intent to limit their children's LNSCl using an intent question developed based on Fishbein \& Ajzen's guidelines [38] and scored using a 7-point Likert scale.

We measured the mothers' behavior of limiting their chiIdren's LNSClusing the short form Food Frequency Questionnaire [43] which we modified to include items unique to this population. Mothers reported how often during the past month they served each simple carbohydrate item listed based on a scale with 9 frequency ranges (never or $<1$ per month to 6 or more per day). Criterion validity and instrument reliability and reproducibility for the original FFQ have been established. Intra-class correlation coefficients for nutrient intakes ranged from 0.41-0.79 [43]. We determined means and standard deviations for specific simple carbohydrate items from the FFQ.

\section{Motivational interviewing intervention}

Our MI intervention was designed to effect behavior change by using abuelas to perform the intervention (addressing perceived norm), sharing information on the benefits of limiting LNSCI (addressing attitude/beliefs), and providing support to increase perceived behavioral control by decreasing mothers' ambivalence and barriers (addressing self-efficacy), which will support intent to limit their children's LNSCl and actual behavior of limiting their children's $\mathrm{LNSCI}$. The abuelas began the $\mathrm{Ml}$ intervention by asking the mothers how they rate the importance of limiting LNSCI on a 0-10 scale. The second question was how the mothers rate their confidence in limiting $\mathrm{LNSCl}$ on a 0-10 scale. If mothers rated the importance of limiting LNSCI low during the MI intervention the abuelas provided them with information on the benefits of limiting $\mathrm{LNSCl}$ to reduce the child's risk of obesity, diabetes, heart disease, and numerous other co-morbidities associated with overweight. If mothers rated their confidence in limiting $\mathrm{LNSCl}$ as low during the $\mathrm{MI}$ intervention then the abuelas provided them with strategies to decrease barriers, such as a list of healthy snack food choices, stepped changes ( 3 sodas per day to 2 sodas and 1 water per day, etc.), and having the child help choose healthy foods at the store, to increase their confidence. To help increase perceived behavioral control (self-efficacy) for limiting LNSCl, the abuela asked them about their readiness to change and what would help them be more successful. We believe the combined influence of changes in attitude/beliefs, perceived norm, and perceived behavioral control (self-efficacy) will increase intent to limit $\mathrm{LNSCl}$ and behavior of limiting LNSCl in Mexican-American mothers receiving the $\mathrm{Ml}$ intervention.

\section{Abuela recruitment and training}

We recruited 2 abuelas based on referrals from our network of community partners and trained them to provide the MI sessions using a 5-hour DVD that demonstrates Miller and Rollnick's [44] technique for assisting with behavioral change. After learning the basic MI technique from the DVD, the senior author (who is MI certified) trained the abuelas specifically to deliver a $\mathrm{Ml}$ intervention to encourage mothers to limit their children's LNSCI. The abuelas participated in role playing practice sessions to develop their proficiency. They followed a written algorithm to ensure uniform implementation of the MI intervention throughout the study. Intervention sessions were audio-recorded, transcribed, and reviewed by the senior author to ensure the accuracy of the MI intervention.

\section{Participant recruitment and retention}

Relationships are critical when working with the MexicanAmerican community. Because of their connections within the community and their respected status, we utilized the abuelas to recruit potential participants. To maximize retention we ensured continuity in the abuela-mother relationships and scheduled interviews at the time most convenient for the participants (including weekends and evenings). Incentives (gift cards) were provided to participants at both intervention/ assessment sessions to encourage participation for the duration of the study. Gift cards compensated participants for their time and could assist mothers in purchasing healthier foods. We used bilingual abuelas and provided all documents in both English and Spanish to accommodate language preferences. Culturally appropriate interactions were emphasized during each data collection using cultural norms of Mexican-American communication.

\section{Informed consent}

We obtained informed consent from both abuelas and mothers who chose to participate. No data was collected until informed consent was completed. The University of Nebraska Medical Center granted IRB approval for this study.

\section{Assessments}

Background information (e.g., age, gender, number of children, education level, income, marital status, years in US, history of family obesity) was collected at baseline only using a demographic questionnaire. All other variables were assessed at baseline and 1 month. Assessments were conducted prior to the delivery of the MI interventions. Attitude/beliefs, perceived norm and perceived behavioral control (self-efficacy) were 
Aguirre et al. Journal of Integrative Psychology and Therapeutics 2013,

Table 1. Means and (standard deviations) for simple carbohydrates showing the greatest change between the baseline and 1 month food frequency questionnaires $(n=6)$.

\begin{tabular}{lcc}
\hline Item & Baseline & 1 Month \\
\hline Soda & $3.83(1.84)$ & $2.67(1.86)$ \\
Fruit drinks & $3.33(2.16)$ & $1.67(1.21)$ \\
$<100 \%$ Fruit juices & $4.33(2.81)$ & $2.50(1.64)$ \\
Lemonade, punch, koolaid & $3.17(2.32)$ & $1.83(1.17)$ \\
Brownies & $2.17(0.98)$ & $1.33(0.52)$ \\
White rice & $3.50(1.38)$ & $2.00(1.10)$ \\
White bread & $3.67(1.37)$ & $1.83(1.33)$ \\
Cold cereal & $4.33(1.51)$ & $2.67(1.21)$ \\
Table sugar & $3.67(2.07)$ & $1.83(1.17)$ \\
\hline
\end{tabular}

measured using sub-scales of the Healthy Diet Survey [3], intent to limit LNSCl was measured using the Intent Questionnaire, and limiting LNSCI behavior was assessed using a short-form food frequency questionnaire. These questionnaires were used to determine changes in mothers' perceptions and behaviors regarding limiting their children's LNSCI.

\section{Data analysis}

A Wilcoxon test $(a=0.05)$ was used to evaluate changes in the mothers' responses to the questionnaires between baseline and 1 month.

\section{Results and discussion}

Although this pilot study was small, it included a diverse sample. Participating mothers ranged in age from 22 to 43 , half were from the U.S. and half were from Mexico, education levels ranged from elementary school to an associate's degree, marital status included single, married or divorced, and annual income levels ranged from $\$ 10,000$ to $\$ 39,000$. All mothers were the primary person responsible for feeding their children. All mothers scored importance of limiting LNSCI for their children as a 9 or 10 (scale of $1-10)(M=9.83$, $\mathrm{SD}=.408$ ) and scored their readiness to change as either highly likely or extremely likely (Likert scale) during both the baseline and 1 month assessments. Confidence scores regarding ability to limit LNSCI for their children increased significantly (Wilcoxon test, $z=-2.041, p=.041$ ) between the baseline $(M=6.33, S D=1.97)$ and 1 month $(M=9.67, S D=.82)$ surveys for 5 of the 6 mothers. The sixth mother scored her confidence as 10 at both assessments and therefore could not increase her score. Though the sample size was a limitation to determining significance, results from the food frequency questionnaires suggest that mothers had reduced the amount of some simple carbohydrates they offered after only 1 month in the study (Table 1).

This study demonstrated that recruitment, retention, and program delivery using abuelas were successful. Each abuela successfully recruited 3 mothers and all 6 mothers participated for the duration of the study. The abuelas were successfully trained in $\mathrm{Ml}$ and reliably delivered the intervention following the algorithm. Results suggest a trend towards mothers limiting their children's LNSCl after just one month of participation.

The abuelas stated that they hope this study continues as they felt it was successful and they were so pleased to be a part of helping their community. Mothers also asked to have the study continue for themselves and others. One mother stated that according to her doctor's scale she lost 8 pounds and her overweight son lost 5 pounds during this one month study. In addition, after just one month of limiting LNSCI her doctor told her and her husband that their blood sugars were under control after years of uncontrolled diabetes.

\section{Study limitations}

This study was limited by its geographical area and restriction to a single ethnic group so that it may not be generalizable to other populations. This pilot study is also limited by its sample size, 2 abuelas and 6 mothers.

\section{Conclusions}

Although from a small sample, these results and participant comments support further evaluation of this approach on a larger scale to fully assess its effectiveness and determine statistical significance. This study demonstrated that recruitment, retention, and program delivery using abuelas were successful and the results suggest a trend towards mothers limiting their children's LNSCI after just one month of participation.

Both mothers and abuelas requested that the program be extended to reinforce the mothers' efforts to limit their children's LNSCI. Therefore, additional booster sessions should be considered. Ml booster sessions have been effective when delivered as often as weekly and as infrequently as 2-3 month intervals $[32,36,45,46]$.

\section{Competing interests}

The authors declare that they have no competing interests.

\section{Authors' contributions}

\begin{tabular}{|l|c|c|c|}
\hline Authors' contributions & TA & SW & AK \\
\hline Research concept and design & $\checkmark$ & -- & -- \\
\hline Collection and/or assembly of data & $\checkmark$ & $\checkmark$ & $\checkmark$ \\
\hline Data analysis and interpretation & $\checkmark$ & -- & -- \\
\hline Writing the article & $\checkmark$ & $\checkmark$ & $\checkmark$ \\
\hline Critical revision of the article & $\checkmark$ & -- & $\checkmark$ \\
\hline Final approval of article & $\checkmark$ & $\checkmark$ & $\checkmark$ \\
\hline Statistical analysis & $\checkmark$ & -- & $\checkmark$ \\
\hline
\end{tabular}

\section{Acknowledgement}

The PI would like to acknowledge her mentor, Dr. Robert Topp, for his guidance during this study. The authors would like to acknowledge the abuelas for this study, Mary Ann Shockley and Vera Lintz. Their hard work and dedication to their community displayed in this study was invaluable. The funding for this study was provided by a 
Aguirre et al. Journal of Integrative Psychology and Therapeutics 2013, http://www.hoajonline.com/journals/pdf/2054-4723-1-1.pdf

Midwest Nursing Research Society mentorship award.

Publication history

Editor: Philip Michael Wilson, Brock University, Canada.

Received: 26-Sep-2013 Revised: 09-Nov-2013

Accepted: 13-Nov-2013 Published: 20-Nov-2013

\section{References}

1. Ogden CL, Carroll MD, Curtin LR, Lamb MM and Flegal KM. Prevalence of high body mass index in US children and adolescents, 2007-2008. JAMA. 2010; 303:242-9. | Article | PubMed

2. Clark L, Bunik M and Johnson SL. Research opportunities with curanderos to address childhood overweight in Latino families. Qual Health Res. 2010; 20:4-14. | Article | PubMed

3. Blue $C L$ and Marrero DG. Psychometric properties of the healthful eating belief scales for persons at risk of diabetes. J Nutr Educ Behav. 2006; 38:134-42. | Article | PubMed

4. Befort CA, Nazir N and Perri MG. Prevalence of obesity among adults from rural and urban areas of the united states: Findings from NHANES (2005-2008). The Journal of Rural Health. 2012; 28:392-397. | Article

5. Nebraska Department of Health and Human Services: Needs assessment. 2011. I Pdf

6. Thomson Medstat Corporation: Childhood obesity: Costs, treatment patterns, disparities in care, and prevalent medical conditions. 2011.

7. Agostoni C, Braegger C, Decsi T, Kolacek S, Koletzko B, Mihatsch W, Moreno LA, Puntis J, Shamir R, Szajewska H, Turck D and van Goudoever J. Role of dietary factors and food habits in the development of childhood obesity: a commentary by the ESPGHAN Committee on Nutrition. J Pediatr Gastroenterol Nutr. 2011; 52:662-9. | Article | PubMed

8. The Merck Manual Home Health Handbook: Carbohydrates, proteins, and fats. 2012. | Website

9. Brekke HK, van Odijk J and Ludvigsson J. Predictors and dietary consequences of frequent intake of high-sugar, low-nutrient foods in 1-year-old children participating in the ABIS study. Br J Nutr. 2007; 97:176-81. | Article | PubMed

10. Starc TJ, Shea S, Cohn LC, Mosca L, Gersony WM and Deckelbaum RJ. Greater dietary intake of simple carbohydrate is associated with lower concentrations of high-density-lipoprotein cholesterol in hypercholesterolemic children. Am J Clin Nutr. 1998; 67:1147-54. | Article | PubMed

11. Corti MC, Guralnik JM, Salive ME, Harris T, Field TS, Wallace RB, Berkman LF, Seeman TE, Glynn RJ, Hennekens CH and et al. HDL cholesterol predicts coronary heart disease mortality in older persons. JAMA. 1995; 274:539-44. | Article | PubMed

12. Daniels SR. Lipid concentrations in children and adolescents: It is not all about obesity. Am J Clin Nutr. 2011; 94:699-700. | Article

13. Welch KR, Ariza AJ, Wieczorek JL and Binns HJ. Characteristics of obese children aged 1-4 years at a referral clinic. J Natl Med Assoc. 2008; 100:884-91. | PubMed

14. Kimbro RT, Brooks-Gunn J and McLanahan S. Racial and ethnic differentials in overweight and obesity among 3-year-old children. Am J Public Health. 2007; 97:298-305. | Article | PubMed Abstract | PubMed Full Text

15. Li C, Goran MI, Kaur H, Nollen N and Ahluwalia JS. Developmental trajectories of overweight during childhood: role of early life factors. Obesity (Silver Spring). 2007; 15:760-71. | Article | PubMed

16. Melgar-Quinonez HR and Kaiser LL. Relationship of child-feeding practices to overweight in low-income Mexican-American preschoolaged children. J Am Diet Assoc. 2004; 104:1110-9. | Article | PubMed

17. Aguirre T, Hudson DB, Weber K, Pozehl B, Boeckner L and Wilhelm S. Mexican American mothers' eating and child feeding behaviors. Issues Compr Pediatr Nurs. 2012; 35:4-23. | Article | PubMed

18. Clark L. Early childhood obesity in Latino families: assembling knowledge for practice. Commun Nurs Res. 2006; 39:15-29. | PubMed
19. Johnson SL. Improving Preschoolers' self-regulation of energy intake. Pediatrics. 2000; 106:1429-35. | Article | PubMed

20. Stunkard AJ and Messick S. The three-factor eating questionnaire to measure dietary restraint, disinhibition and hunger. J Psychosom Res. 1985; 29:71-83. | Article | PubMed

21. Contento IR, Zybert $P$ and Williams SS. Relationship of cognitive restraint of eating and disinhibition to the quality of food choices of Latina women and their young children. Prev Med. 2005; 40:326-36. | Article I PubMed

22. Ventura AK and Birch LL. Does parenting affect children's eating and weight status? Int J Behav Nutr Phys Act. 2008; 5:15. | Article | PubMed Abstract I PubMed Full Text

23. Salsberry PJ and Reagan PB. Dynamics of early childhood overweight. Pediatrics. 2005; 116:1329-38. | Article | PubMed Abstract | PubMed Full Text

24. Wofford LG. Systematic review of childhood obesity prevention. J Pediatr Nurs. 2008; 23:5-19. | Article | PubMed

25. Waters E, de Silva-Sanigorski A, Hall BJ, Brown T, Campbell KJ, Gao Y, Armstrong $R$, Prosser $L$ and Summerbell $C D$. Interventions for preventing obesity in children. Cochrane Database Syst Rev. 2011; CD001871. | Article | PubMed

26. Lavelle HV, Mackay DF and Pell JP. Systematic review and meta-analysis of school-based interventions to reduce body mass index. J Public Health (Oxf). 2012; 34:360-9. | Article | PubMed

27. Branscum $P$ and Sharma M. A systematic analysis of childhood obesity prevention interventions targeting Hispanic children: lessons learned from the previous decade. Obes Rev. 2011; 12:e151-8. | Article | PubMed

28. Perez-Morales ME, Bacardi-Gascon M and Jimenez-Cruz A. Childhood overweight and obesity prevention interventions among Hispanic children in the United States: systematic review. Nutr Hosp. 2012; 27:1415-21. | Article | PubMed

29. Ramirez M, Ford ME, Stewart AL and Teresi JA. Measurement issues in health disparities research. Health Serv Res. 2005; 40:1640-57. | Article | PubMed Abstract | PubMed Full Text

30. Riddell $L$, Ang B, Keast RS and Hunter W. Impact of living arrangements and nationality on food habits and nutrient intakes in young adults. Appetite. 2011; 56:726-31. | Article | PubMed

31. Centers for Disease Control. Vital signs telebriefing: State-specific obesity prevalence among adults - united states, 2009. 2010. I Website

32. Borrelli B, McQuaid EL, Novak SP, Hammond SK and Becker B. Motivating Latino caregivers of children with asthma to quit smoking: a randomized trial. J Consult Clin Psychol. 2010; 78:34-43. | Article | PubMed

33. Franzen-Castle L, Aguirre T and Boci A. Perceptions of body image and cultural health among hispanic adults. Journal of the Academy of Nutrition and Dietetics. 2012; 112:20. | Article

34. Miller WR, Rollnick SP. Motivational interviewing: Preparing people for change. The Guilford Press. 2002. I Book

35. Bernstein J, Bernstein E, Tassiopoulos K, Heeren T, Levenson S and Hingson R. Brief motivational intervention at a clinic visit reduces cocaine and heroin use. Drug Alcohol Depend. 2005; 77:49-59. I Article I PubMed

36. Rocha-Goldberg Mdel P, Corsino L, Batch B, Voils Cl, Thorpe CT, Bosworth HB and Svetkey LP. Hypertension Improvement Project (HIP) Latino: results of a pilot study of lifestyle intervention for lowering blood pressure in Latino adults. Ethn Health. 2010; 15:269-82. | Article | PubMed Abstract I PubMed Full Text

37. Stuckey HL, Dellasega C, Graber NJ, Mauger DT, Lendel I and Gabbay RA. Diabetes nurse case management and motivational interviewing for change (DYNAMIC): study design and baseline characteristics in the Chronic Care Model for type 2 diabetes. Contemp Clin Trials. 2009; 30:366-74. | Article | PubMed Abstract | PubMed Full Text

38. Fishbein $\mathrm{M}$ and Ajzen I. Predicting and changing behavior. Psychology Press. 2010. | Book 
Aguirre et al. Journal of Integrative Psychology and Therapeutics 2013,

39. Conn VS, Tripp-Reimer T and Maas ML. Older women and exercise: theory of planned behavior beliefs. Public Health Nurs. 2003; 20:153-63. | Article | PubMed

40. Lopez-McKee G. Development of the mammography beliefs and attitudes questionnaire for low-health-literacy Mexican-American women. Online J Issues Nurs. 2011; 16:7. I Article I PubMed

41. Martin JJ, Oliver K and McCaughtry N. The theory of planned behavior: predicting physical activity in Mexican American children. J Sport Exerc Psychol. 2007; 29:225-38. I PubMed

42. Palmeira AL, Teixeira PJ, Branco TL, Martins SS, Minderico CS, Barata JT, Serpa SO and Sardinha LB. Predicting short-term weight loss using four leading health behavior change theories. Int J Behav Nutr Phys Act. 2007; 4:14. | Article | PubMed Abstract | PubMed Full Text

43. Willett WC, Sampson L, Stampfer MJ, Rosner B, Bain C, Witschi J, Hennekens $\mathrm{CH}$ and Speizer FE. Reproducibility and validity of a semiquantitative food frequency questionnaire. Am J Epidemiol. 1985; 122:51-65. | Article | PubMed

44. Miller W and Rollnick S. Motivational interviewing. Professional Training Series. 1998. | Website

45. McPherson D. Motivational interviewing seeks specific solutions. 2004. I Website

46. Robles RR, Reyes JC, Colon HM, Sahai H, Marrero CA, Matos TD, Calderon JM and Shepard EW. Effects of combined counseling and case management to reduce HIV risk behaviors among Hispanic drug injectors in Puerto Rico: a randomized controlled study. J Subst Abuse Treat. 2004; 27:145-52. | Article | PubMed

\section{Citation:}

Aguirre T, Wilhelm S and Koehler A. Abuela to mother motivational interviewing intervention to reduce low-nutritive simple carbohydrate intake.

J Integr Psychol Ther. 2013; 1:1.

http://dx.doi.org/10.7243/2054-4723-1-1 